\title{
VALUE OF POOLED GASTRO-INTESTINAL NEMATODE COPRO- ANTIGENS IN THE DIAGNOSIS OF INHIBITED LARVAE INFECTION IN EGYPTIAN SHEEP
}

By

\author{
HEND M. AUDA ${ }^{1}$, MARWA M. KHALIFA ${ }^{2^{*}}$, MAHMOUD M. AMIN ${ }^{1}$
}

AND MOHAMED M. EL BAHY ${ }^{2}$

Department of Medicine and Infectious Diseases ${ }^{1}$ and Department of Parasitology ${ }^{2}$, Faculty of Veterinary Medicine, Cairo University, Giza, Egypt

( ${ }^{\star}$ Correspondence: marwaehab40@yahoo.com)

\section{Abstract}

Parasitic gastroenteritis (PGE) infecting sheep in acute or chronic forms causes severe economic losses. Infections by adult worms can be easily diagnosed and controlled, but infection by migrating and inhibited larvae are difficult to diagnose. Detection of anti-parasite antibodies in sera of infected animals needs special Ag for each species and presence of antibodies in sera does not reflect the actual infection. This study evaluated diagnostic efficacy of two pooled Copro $\mathrm{Ag}(\mathrm{s})$ prepared from feces of PGE infected sheep with larval5 species (Haemonchus spp., Trichostrongylus spp., Nematodirus spp., Cooperia spp. \& Ostertagia spp.) in sheep. Diagnostic values of pooled $\operatorname{Ag}(\mathrm{s})$ were compared with two separate worm $\operatorname{Ag}(\mathrm{s})$ (Haemonchus spp. \& Trichostrongylus spp.) using indirect and antigen capture ELISA. The results showed high sensitivity for pooled Copro and larval $\mathrm{Ag}(\mathrm{s})$ than individual parasitic $\mathrm{Ag}(\mathrm{s})$ in detecting $\mathrm{Ab}(\mathrm{s})$ in infected animals. Copro Ag showed high sensitivity $(87.69 \%)$ than larval Ag (75.38\%). For Haemonchus and Trichostrongylus Ag was $44.62 \%$ \& $32.31 \%$ respectively. Pooled larval antigen showed high specificity (86.66\%) than Copro Ag (78.33\%), without cross reaction with non-infected controls. In migrating and inhibited larvae, pooled $\mathrm{Ag}$ showed $80 \%$ sensitivity in detecting PGE circulating antigen in animals without eggs in feces compared to $30 \%$ sensitivity using pooled Copro antigen by sandwich ELISA. Positive animals shed eggs in feces during follow up prior to parturition. Diagnosis of inhibited larvae circulating $\mathrm{Ag}(\mathrm{s})$ using pooled larval antigen was promising method in expecting time of autoinfection of sheep due to activation of arrested larvae within the bodies. This facilitated their therapeutic treatment at a critical time before the sudden re-appearance of infection.

Keywords: Parasitic gastroenteritis, sheep, Copro antigens, ELISA.

\section{Introduction}

Parasitic Gastro-enteritis (PGE) is a widespread risky problem caused by Nematodes (order Strongyloidea) including many species as Trichostrongylus spp., Ostertagia spp., Haemonchus spp., Cooperia spp., and Nematodirus spp. infecting several hosts including ruminants (Roeber et al, 2013). The lambs parasites caused weight loss and reduction in productivity or even mortalities (Islam et al, 2017). Haemonchus contortus (blood-sucking parasite) caused significant blood loss $(0.05 \mathrm{ml} /$ day $)$, a decrease in erythrocytes, lymphocytes, hemoglobin, anemia and PCV (Gadahi et al, 2009). Under unfavorable conditions, usually at the end of the grazing season the third larval $\left(\mathrm{L}_{3}\right)$ stage during passage via stomach, loses its protec- tive sheath, migrates in tissues transformed to a tissue or histotropic phase (hypobiotic), inhibited or arrested larvae. They undergo a period of arrested development prior to be $\mathrm{L}_{4}$ and pre-adult stages. Tissue larvae resume activity and development in ewes in synchrony with the lambing season, causing a peri-parturient increase in fecal egg counts (FECs), contaminating pasture with $\mathrm{L}_{3}$ stage that infects the animals while grazing (Roeber et al, 2013). Hypobiotic larvae infect animals causing clinical manifestations (Meradi et al, 2016). Gold standard diagnosis is microscopic examination (McHardy et al, 2014). But, it has several disadvantages as being time consuming, unreliable, unable to detect pre-patent infections and dependent on skilled technician (Mancera et al, 2016). 
Due to morphological similarity of PGE eggs, fecal examination must followed by fecal culture to identify larvae, as there was no absolute correlation between worm burden and egg output (Demeler et al, 2010).

ELISA is an easily applicable serological test to evaluate a large number of samples, with accuracy depends on antigen degree of purity and specificity. It detects specific anti-parasite antibodies (AP-Ab) or circulating parasite antigens in sera or in feces (Sun et $a l, 2015)$. Parasite circulating antigens open a new field for accurate diagnosis of infection as circulating antigens is related to active infection (Johnson et al, 2004). The host usually contains different mixed infection, which deposit more or less similar eggs in feces and mixed forms of migrating larvae. Other than Haemonchus species, there are problems in preparation of pure specific Ag for each species indicated for serodiagnosis (El-Bahy et al, 2007). ELISA is a must for capturing antigens and reflect infection as being sensitive, easy to use, without expert microscopist.

The present study aimed to evaluate the diagnostic efficacy of two Copro-antigens prepared from feces of sheep heavily infected by different species of PGE identified by fecal culture. Two antigens, one was prepared from the whole PGE highly infected feces and second from pooled cultivated larvae. Diagnostic efficacy of both antigens in comparison with the other two PGE individual parasite $\operatorname{Ag}(\mathrm{s})$ was evaluated in detecting anti-PGE antibodies and PGE C-Antigens in sera of infected and suspected sheep using two types of ELISA. Inspecting animals that do not have PGE eggs in feces will be investigate to evaluate the efficacy of the used antigens in diagnosing the presence of inhibited larvae in these animals.

\section{Materials and Methods}

Animals: A total of 30 naturally infected sheep (fecal examination) and 30 jugular blood samples were selected during two years investigation of 275 naturally infected sheep from Giza Governorate. They were divided into groups: GI: 20 sheep with low levels of PGE nematode infection (100-500eggs/gram feces or epg). GII: 20 sheep shedding 5001000epg. GIII: 25 sheep shedding over 1000 epg. PGE nematode larvae in feces identified by fecal culture (Anamnart et al, 2015) GIV: 40 sheep (1-4 years old) parasite-free were selected from the previously examined animals (275). GIV was used to evaluate the antigens in diagnosing the parasitic stages of inhibited and/or tissue migrating larvae especially in ELISA positive animals. Appearance of PGE eggs in feces were followed up for enough periods after this.

For testing antigenic specificity, another four groups of sheep, each with single infection with another parasite detected by feces was divided into: GV: 15 sheep with Fasciola eggs, GVI: 10 sheep with Paramphistomum eggs, GVII: 15 sheep with Moniezia eggs and GVIII: 20 sheep with Eimeria oocysts. Fluke finder technique was used to diagnose Fasciola \& Paramphistomum (Foreyt, 2005). Ten suckling lambs (2-3 weeks old) parasite-free were used as negative controls.

Fecal examination: Nematode eggs were counted for each sample by Mc-Master technique (Soulsby, 1986). Cultivated larvae were collected by modified Baermann technique (Foreyt, 2005), and identified (Wyk and Mayhew, 2013). Larvae were counted/ sheep \&mean number/sheep in each group.

PGE Copro antigens of eggs and larvae: After cultivation of several heavily infected sheep (2000-4000/epg), five fecal samples with a high level of different PGE nematode larvae were selected. Fecal samples (5gm) with different eggs were mixed well with an equal amount of $0.01 \mathrm{M}$ PBS, PH 7.4 and processed for PGE eggs Copro antigen preparation (El-Bahy et al, 1992). After cultivation of pooled fecal samples from the previous five animals, a large amount of mixed larvae species (Tab. 1) was collected by Baermann technique. Larvae were washed using PBS and centrifugation (3000 rpm $/ 3 \mathrm{~min}$ ). After removal of supernatant, larvae were 
mixed with an equal amount of PBS, homogenized at 6000rpm for 20 minutes in an ice bath (Ultra-Turrax Janke \& Kunkel KG), and sonicated by sonifier cell disrupter. Soluble antigen was separated by centrifugation (20000rpm) for $1 \mathrm{hr}$ at $4^{\circ} \mathrm{C}$. Supernatant was separated as a crude soluble antigen used as pooled larval Copro-antigen. Protein content was determined (Lowry et al, 1951), allocated in $1 \mathrm{ml}$ vial and stored at $-20^{\circ} \mathrm{C}$ until used.

Crude antigens of Haemonchus, Trichostrrongylus, Moniezia scolices and Paramphistomum anterior sucker areas were separated from living worms collected from freshly slaughtered animals for antigen preparation. Fasciola excretory/secretory (ES) antigen was prepared (Khabisi et al, 2017)

Reference control serum: Sera of three sheep highly infected by PGE nematodes only and ten samples from parasite-free suckling lambs were used as reference positive and negative control.

Reference rabbit and rat hyper-immune serum (HIS): four $250 \mathrm{gm}$ rats and 4 one and half $\mathrm{Kg}$ rabbits were used as production of reference PGE hyper-immune sera vs. PGE Copro and larval $\operatorname{Ag}(\mathrm{s})$ (two rat and two rabbits for each Ag), Each animal was exposed to initial $\mathrm{S} / \mathrm{C}$ injection followed by three consecutive intramuscularly injections of calculated dose of the Ag in an equal volumes of mineral oil during 4-5 weeks (Shalaby et al, 2014). Specific antibodies level in sera of immunized animals was evaluated 710 days after last poster dose before being slaughtered using indirect ELISA.

Indirect ELISA: Selected antigens, serum, and conjugate concentrations were determined after checkerboard titration. Positive ELISA equal to mean of negative control \& 2 folds of standard deviation (Zimmerman et al, 1982). Sensitivity and specificity were evaluated after screening of selected sheep serum samples of low epg., high epg., and of other parasites (Attallah et al, 1997).

Sandwich (antigen capture) ELISA: PGE circulating antigens in suspected animal serum samples were detected using two anti- bodies sandwich ELISA. Tested conditions were adjusted after checkerboard titrations as before. High binding flat-bottom 96-well micrometer plates were coated with $100 \mu \mathrm{l} /$ well of 1:100 Rat HI serums (first reference serum) diluted in $0.1 \mathrm{ml}$ carbonate buffer $(\mathrm{pH}$ 9.6). Plates were incubated overnight at $4^{\circ} \mathrm{C}$. After washing, two replicate of each tested suspected animal serum (1:50) were added and incubated for $3 \mathrm{hrs}$ at $37^{\circ} \mathrm{C}$. After washing $100 \mu \mathrm{l} /$ well of the prepared Rabbit HI serum (second reference serum) (1:100 diluted in PBS) was added, then incubation at room temperature for $2 \mathrm{hrs}$. After washing, $100 \mu \mathrm{l}$ of horse reddish peroxidase conjugate sheep anti-rabbit IgG, diluted 1:1000 within PBS was added to each well and incubated for $1 \mathrm{hr}$. After washing, $100 \mu \mathrm{l}$ of O-phenylene diamine dihydrochloride substrate was added to each well. Reaction was left for $15 \mathrm{mi}$ nutes at room temperature in dark and color change was measured (Liu et al, 2013).

Ethical approval: All steps and procedures were approved by the Institutional Animal Care \& Use ethical Committee (CUIACUC), Cairo University. The study was done from August 2017 to July 2019 in Parasitology Laboratory, Faculty of Veterinary Medicine.

\section{Results}

In the present study, two types of pooled PGE Copro-antigens (Copro Ag from feces of naturally heavily infected sheep and another pooled Ag prepared from different larvae obtained after cultivation of the previous infected fecal samples) as well as two individual parasite $\operatorname{Ag}(\mathrm{s})$ of Haemonchus and Trichostrongylus spp. were evaluated to diagnose apparent and in-apparent infection by these parasites in sheep. For these reasons, the investigated sheep were selected to be containing known different levels of infection as described in table1. Fecal examination of these selected sheep proved to be infected only by PGE nematodes after two successive investigations. They were allocated as GI contained 20 animals of low infection level with mean epg (300). GII contained 20 sheep of moderate infection level 
with mean epg (650) and GIII with high infection level with mean epg (1850) among them five animals which were infected by more than 3500epg. Cultivation of fecal samples from all animals represented a different percentage of infection by five species of larvae as Haemonchus spp., Trichostrongylus spp., Nematodirus spp., Cooperia spp. and Ostertagia spp. A group of 40 animals (GIV) was selected which were free from PGE infection or larvae after cultivation of their fecal samples (Tab. 1)

Sensitivity of tested $\mathrm{Ag}(\mathrm{s})$ diagnosing antiPGE $\mathrm{Ab}(\mathrm{s})$ in sera by indirect ELISA: Evaluating sensitivity of the previous four PGE $\mathrm{Ag}(\mathrm{s})$ in capturing the specific anti-PGE antibodies (PGE-Ab) in sera of sheep infected by different levels of parasites showed that Copro-egg Ag gave higher sensitivity (80$92 \%)$ with mean $(87.69 \%)$ as compared with larva-Ag (70\%-80\%) with mean (75.38\%). There was a direct relation between mean epg in tested group and level of detected $\mathrm{Ab}(\mathrm{s})$ in the sera. Screening of same sera vs. Haemonchus worm-Ag gave low mean sensitivity (44.62\%) as compared with the other two antigens while Trichostrongylus crude $\mathrm{Ag}$ was able to diagnose PGE $\mathrm{Ab}(\mathrm{s})$ in sera of $25-40 \%$ of inspected animals with mean sensitivity up to $32.31 \%$. No cross-reaction by using $\operatorname{Ag}(\mathrm{s})$ versus sera collected from 23 weeks old control lambs (Tab. 2).

Specificity of $\operatorname{Ag}(\mathrm{s})$ in diagnosis of antiPGE Ab(s) in sera by ELISA: Testing speci ficity of these $\operatorname{Ag}(\mathrm{s})$ in capturing $\mathrm{Ab}(\mathrm{s})$ of other parasites in groups of infected sheep showed that the antigens extracted from the pooled species of larvae gave higher mean specificity $(86.66 \%)$ than that of Copro-Ag (78.33\%). Both $\mathrm{Ag}(\mathrm{s})$ showed same specificity vs. anti-Fasciola, or Paramphistomum or Moniezia Ab(s) (86.66\%-80.0\%-86.66\%). Main difference between them was low level of cross-reaction recorded using pooled larva-Ag vs. anti-Eimeria $\mathrm{Ab}(\mathrm{s})$ infected sheep. Also, separate Haemonchus and Trichostrongylus $\mathrm{Ag}(\mathrm{s})$ showed high mean specificity of $90 \%$ \& $91.7 \%$ respectively (Tab. 3).

Determination of specific circulating PGE $\mathrm{Ag}(\mathrm{s}) \& \mathrm{Ab}(\mathrm{s})$ in sera of sheep by ELISA and Sandwich ELISA: Both tested pooled Ag(s) were used to diagnose suspected PGE infection didn't have eggs in feces. The 40 sheep without PGE eggs in feces were tested for circulating PGE Ab(s) using ELISA for PGE circulating $\mathrm{Ag}(\mathrm{s})$ in sera using antigen capture ELISA (sandwich) after preparation of required reference HIS by both pooled Ag. Sheep (17.5\% \& $12.5 \%)$ showed anti-parasite $\mathrm{Ab}(\mathrm{s})$ versus both Copro-egg and larval antigens respectively. Re-examinationto detect PGE circulating $\mathrm{Ag}(\mathrm{s})$ in sera showed that $30 \%$ reacted positive versus the pooled Copro-Ag, but 32 sheep (80\%) from them reacted positively vs. pooled larval Ag. Following up, 32 sheep had a true infection by inhibited larvae and shed PGE eggs 1-2 weeks before parturition in each case (Tab. 4).

Table 1: Level of PGE eggs and mean \% of larval types in feces of sheep groups selected for evaluation.

\begin{tabular}{|c|c|c|c|c|c|c|c|c|}
\hline \multirow{3}{*}{ Group } & \multirow{3}{*}{$\begin{array}{l}\text { No. of } \\
\text { Animal }\end{array}$} & \multicolumn{7}{|c|}{ Mean $\%$ of different larvae in 100 counted larvae } \\
\hline & & \multicolumn{2}{|c|}{$\begin{array}{l}\text { Total PGE eggs } \\
\text { Detected (epg) }\end{array}$} & \multirow{2}{*}{$\begin{array}{c}\text { Haemonchus } \\
\text { spp. } \\
\text { Mean } \% \\
\end{array}$} & \multirow{2}{*}{$\begin{array}{c}\text { Trichostrongylus } \\
\text { spp. } \\
\text { Mean } \% \\
\end{array}$} & \multirow{2}{*}{$\begin{array}{c}\text { Nematodirus } \\
\text { spp. }\end{array}$} & \multirow{2}{*}{$\begin{array}{c}\text { Cooperia } \\
\text { spp. } \\
\text { Mean } \%\end{array}$} & \multirow{2}{*}{$\begin{array}{c}\text { Ostertagia } \\
\text { spp } \\
\text { Mean \% }\end{array}$} \\
\hline & & Low-high & Mean No. & & & & & \\
\hline G I & 20 & $100-500$ & 300 & 36 & 18 & 10 & 11.0 & 24 \\
\hline G II & 20 & $500-1000$ & 650 & 29 & 24 & 12 & 8 & 27 \\
\hline G III & 25 & Over 1000 & 1850 & 32 & 26 & 14 & 12 & 16 \\
\hline G IV & 40 & -ve & -ve & - & - & - & - & - \\
\hline
\end{tabular}

Table 2: Sensitivity of different $\mathrm{Ag}(\mathrm{s})$ in diagnosing anti-PGE Ab(s) in sera of PGE infected sheep using ELISA.

\begin{tabular}{|c|c|c|c|c|c|c|c|c|c|}
\hline \multirow{3}{*}{$\begin{array}{c}\text { Group No. } \\
\text { And average PGE epg }\end{array}$} & \multirow{3}{*}{$\begin{array}{c}\text { Animal } \\
\text { No. }\end{array}$} & \multicolumn{8}{|c|}{ ELISA results at (1:100 serum dilute) versus } \\
\hline & & \multicolumn{2}{|c|}{$\begin{array}{c}\text { PGE } \\
\text { Copro Ag }\end{array}$} & \multicolumn{2}{|c|}{$\begin{array}{l}\text { PGE pooled larval } \\
\mathrm{Ag}\end{array}$} & \multicolumn{2}{|c|}{$\begin{array}{l}\text { Haemonchus spp. } \\
\text { crude Ag }\end{array}$} & \multicolumn{2}{|c|}{$\begin{array}{c}\text { Trichostrongylus spp. } \\
\mathrm{Ag}\end{array}$} \\
\hline & & $\mathrm{No}+\mathrm{ve}$ & $\%$ & $\mathrm{No}+\mathrm{ve}$ & $\%$ & $\mathrm{No}+\mathrm{ve}$ & $\%$ & $\mathrm{No}+\mathrm{ve}$ & $\%$ \\
\hline G I $100-500$ & 20 & 16 & 80 & 14 & 70 & 8 & 40 & 5 & 25 \\
\hline G II 500- 1000 & 20 & 18 & 90 & 16 & 80 & 10 & 50 & 8 & 40 \\
\hline G III $>1000$ & 25 & 23 & 92 & 19 & 76 & 11 & 44 & 8 & 32 \\
\hline Mean Sensitivity \% & 65 & 57 & 87.69 & 49 & 75.38 & 29 & 44.62 & 21 & 32.31 \\
\hline Non infected suckling lamb & 10 & 0 & - & 0 & - & 0 & - & 0 & - \\
\hline
\end{tabular}


Table 3: Specificity of $\mathrm{Ag}(\mathrm{s})$ in diagnosing anti-PGE $\mathrm{Ab}(\mathrm{s})$ in sera using ELISA.

\begin{tabular}{|c|c|c|c|c|c|c|c|c|c|}
\hline \multirow{3}{*}{$\begin{array}{c}\text { Sera from } \\
\text { sheep infected } \\
\text { only by }\end{array}$} & \multirow{3}{*}{$\begin{array}{l}\text { Animal } \\
\text { No. }\end{array}$} & \multicolumn{8}{|c|}{ ELISA results at (1:100 serum dilute) versus } \\
\hline & & \multicolumn{2}{|c|}{$\begin{array}{c}\text { PGE } \\
\text { Copro Ag }\end{array}$} & \multicolumn{2}{|c|}{$\begin{array}{l}\text { PGE pooled } \\
\text { larval } \mathrm{Ag}\end{array}$} & \multicolumn{2}{|c|}{$\begin{array}{l}\text { Haemonchus spp } \\
\text { crude Ag }\end{array}$} & \multicolumn{2}{|c|}{$\begin{array}{c}\text { Trichostrongylus spp } \\
\text { Ag. }\end{array}$} \\
\hline & & $+\mathrm{ve}$ & $\%$ & $+\mathrm{ve}$ & $\%$ & $+\mathrm{ve}$ & $\%$ & $+\mathrm{ve}$ & $\%$ \\
\hline Fasciola & 15 & 2 & 86.66 & 2 & 86.66 & 2 & 86.66 & 2 & 86.66 \\
\hline Paramphistomum & 10 & 2 & 80 & 2 & 80 & 1 & 90 & 1 & 90 \\
\hline Moniezia & 15 & 2 & 86.66 & 2 & 86.66 & 1 & 93.33 & 1 & 93.33 \\
\hline Eimeria & 20 & 7 & 65 & 2 & 90 & 2 & 90 & 1 & 95.0 \\
\hline Mean specificity $\%$ & 60 & 13 & 78.33 & 8 & 86.66 & 6 & 90 & 5 & 91.7 \\
\hline
\end{tabular}

Table 4: Specific circulating PGE $\operatorname{Ag}(\mathrm{s}) \& \mathrm{Ab}(\mathrm{s})$ in sera of suspected sheep by ELISA \&Sandwich ELISA.

\begin{tabular}{|c|c|c|c|c|c|}
\hline \multirow{2}{*}{ Technique used } & \multirow{2}{*}{ No. of animals } & \multicolumn{4}{|c|}{ No \&\% of +ve animals versus } \\
\cline { 3 - 6 } & & Copro Ag containing eggs & Copro-larval Ag \\
\cline { 3 - 6 } & & No. & $\%$ & No. & $\%$ \\
\hline \multirow{2}{*}{ Indirect ELISA } & 40 non-infected & 7 & 17.5 & 5 & 12.5 \\
\cline { 2 - 6 } & 10 suckling & 0 & & 0 & \\
\hline \multirow{2}{*}{ Sandwich ELISA } & 40 non-infected & 12 & 30 & $32^{*}$ & 80 \\
\cline { 2 - 6 } & 10 suckling & 0 & & 0 & \\
\hline
\end{tabular}

* All animals shed PGE eggs in feces prior to parturition in each case.

\section{Discussion}

Diagnosis of PGE infection depends on microscopical determination of fecal egg counts. This method is hindered by several disadvantages as labor intensive, skilled microscopists and relatively unreliable (Mancera et al, 2016). The output of eggs did not usually correlated with the worm burden and eggs were not uniformly distributed in fecal samples. Coprological examination neither diagnose parasite during pre-patent period nor gave data about the arrested or inhibited larvae in animal body (Demeler et al, 2010).

Diagnosis of PGE infection by coprological examination was considered an easy method (Rojas et al, 2014), with a problem if suspecting animals didn't pass eggs in feces. Serodiagnosis by detection of specific parasite circulating antibodies using a technique like indirect ELISA proved an easy method, but needed some specific Ag (Sun et al, 2015). Circulating antibodies in serum cannot differentiate between old and recent infection where they can still for a certain period post-treatment (Mezo et al, 2004). PGE group usually infect the same animal by more than 3-5 species together and preparation of separate antigen from each species was considered difficult (El-Bahy et al, 2007). The present results showed high sensitivity for the pooled Copro and larval $\operatorname{Ag}(\mathrm{s})$ than the individual parasitic $\operatorname{Ag}(\mathrm{s})$ in detection parasite $\mathrm{Ab}(\mathrm{s})$ in sera of infected animals. Copro Ag showed higher sensitivity $(87.69 \%)$ than larval $\mathrm{Ag}(75.38 \%)$. While for Haemonchus Ag sensitivity was $44.62 \%$ and for Trichostrongylus Ag was 32.31\%. Meanwhile, no-cross reaction was recorded by using any of these $\mathrm{Ag}(\mathrm{s})$ versus noninfected control lambs. High superiority of Copro Ag than pooled larval Ag agreed with Rojas et al. (2014), Mancera et al. (2016) and Little et al. (2019) as Copro Ag contained excretory, secretary products and some eggs produced directly from worms in alimentary tracts. These $\mathrm{Ab}(\mathrm{s})$ in serum were directly related to the reaction of body versus adult worms as compared with the antigenic constituents of larvae hatched from eggs outside the body. The present lower sensitivity of individual $\mathrm{Ag}(\mathrm{s})$ of Haemonchus and Trichostrongylus spp. can be att ributed to the recorded percentage of the larvae in fecal culture of examined animals. These two antigens showed a special tendency to diagnose $A b(s)$ related to $t$ adult worm percentage in animals groups. Thus, the pooled mixed Copro Ag must exceed the efficacy of this single species Ag in tdetection of PGE specific $\mathrm{Ab}(\mathrm{s})$.

In the present study, both pooled Copro and larval $\operatorname{Ag}(\mathrm{s})$ have same specificity versus $\mathrm{Ab}(\mathrm{s})$ against Fasciola, Paramphistomum and Moniezia. Main difference was the 
low level of cross-reaction by using pooled larval Ag versus anti-Eimeria $\mathrm{Ab}(\mathrm{s})$. Decreased specificity of Copro Ag to (78.33\%), but that of larval Ag was (86.66\%). Also, individual Haemonchus and Trichostrongylus $\mathrm{Ag}(\mathrm{s})$ showed high specificity; 90\% \& 91.7\% respectively. Undoubtedly, PGE egg Ag(s) among Copro Ag caused this crossreaction with Eimeria. The cross-reaction in animals infected by Fasciola or Paramphistomum or Moniezia versus both pooled Ag (s) of PGE was related to previous infection. Presence of eggs as compartments from Copro Ag was reported (El-Bahy et al, 1992). The high specificity of individual $\operatorname{Ag}(\mathrm{s})$ of Haemonchus and Trichostrongylus in comparison with that obtained by using pooled Copro Ag or larval Ag was acceptable to contain more specific characteristic epitopes (in single parasite) than in pooled $\operatorname{Ag}(\mathrm{s})$.

With the superiority of pooled Copro Ag in diagnosis of anti-PGE antibodies in animals' sera without eggs in feces, detection of circulating $\mathrm{Ab}(\mathrm{s})$ without value in suspecting future infection that did not passs eggs in feces. This may be attributed to the ability of the previous antibodies to remain for a period post-treatment and didn't relate to active infection (Mezo et al, 2004). Thus, antibody detecting ELISA was unable to suspect infection by arrested or inhibited larvae. The presence of inhibited larvae can become active and induce self-infection to animal causing severe problems especially with animal exposure to stress factors as prior to parturition in pregnant ewes. This agreed with Roeber et al. (2013) who found that hypobiosis, inhibition or arrested development causes a delay in parasite development in host, led to infection reappearance at a suitable time of the bad health condition of the infected hosts. They added that arrested larvae in intestinal tissues acted as a source of new infection even with the application of restricted control measures. Altif and Issa (1983) found that high re-infection in sheep by PGE coincided with lambing period related to release of inhibited larvae. But, presence of circulating $\operatorname{Ag}(\mathrm{s})$ in sera and/or in feces was related to active infection by the target parasite (Attalah et al, 2013).

In the present study, circulating anti-PGE $\mathrm{Ab}(\mathrm{s})$ was recorded in $17.5 \%$ and $12.5 \%$ of sheep versus both $\operatorname{Ag}(\mathrm{s})$ respectively using indirect ELISA, diagnosis of the circulating $\operatorname{Ag}(\mathrm{s})$ in sera of sheep using S-ELISA revealed that $30 \%$ (12 animals) of 40 sheep reacted positively versus pooled Copro $\mathrm{Ag}$, and $80 \%$ of which 32 reacted positively versus pooled larval Ag. The 32 animals had a true infection by inhibited larvae as they shed PGE eggs in feces at 1-2 weeks before parturition. But, superiority of Copro Ag to diagnose specific $A b(s)$ in sheep sera sheding PGE eggs, larval Ag gave high sensitivity to detect PGE circulating $\mathrm{Ag}(\mathrm{s})$ in those without eggs in feces. Ability of larval Ag to show infection by migrating or inhibited larvae was more important in preventing sudden infection in parasite-free animals.

\section{Conclusion}

Copro-antigen allowed for rapid screening capacity, in surveillance with high sensitivity and specificity to diagnose specific parasite $A b(s)$ in sera but with low value in diagnosing inhibited larvae.

Pooled larval Ag after use of specific HIS in sheep is a new sensitive and specific method for PGE characteristic circulating $\mathrm{Ag}(\mathrm{s})$ in suspected sheep using S-ELISA, detected infection by inhibited larvae in sheep not passing eggs.

\section{References}

Altaif, KI, Issa, WH, 1983: Seasonal fluctuations and hypobiosis of gastro-intestinal nematodes of Awassi lambs in Iraq. Parasitology 86: 301-10.

Anamnart, W, Intapan, PM, Pattanawongsa, A, Chamavit, P, Kaewsawat, S, et al, 2015: Effect of dilution of stool soluble component on growth and development of Strongyloidesstercoralis. Sci. Rep. Jun 2; 5:10749. doi: 10.1038/ srep10749.

Attallah, AM, Bughdadi, FA, El-Shazly, AM, Ismail, H, 2013: Immunodetection of Fasciola gigantica circulating antigen in sera of infected individuals for laboratory diagnosis of human fa- 
scioliasis. Clin. Vac. Immunol. 20, 10:1569-77. Attallah, AM, El-Masry, SA, Rizk, H, Ismail, H, El-Bendary, M, et al, 1997: Fast-Dot ELISA using urine, a rapid and dependable field assay for diagnosis of schistosomiasis. J. Egypt. Soc. Parasitol. 27, 1:279-89

Demeler, J, Kuttler, U, El-Abdellati, A, Stafford, K, Rydzik, A, et al, 2010: Standardization of the larval migration inhibition test for the detection of resistance to ivermectin in gastrointestinal nematodes of ruminants. Vet. Parasitol. 174:58-64.

El-Bahy, MM, El-Bahy, NM, Shalaby, HA 2007: Value of Haemonchuslongistipes purified antigens in the diagnosis of gastro-intestinal nematodes infection in camels. Pakis. J. Biol. Sci. 10, 9:1452-8.

El-Bahy, MM, Malone, JB, Todd, WJ, Schnorr, KL, 1992: Detection of stable diagnostic antigen from bile and feces of Fasciola hepatica infected cattle. Vet. Parasitol. 45:157-67.

Foreyt, WJ, 2005: Parasitologia Veterinária: Manual de Referência. $5^{\text {th }}$ ed. São Paulo: Roca.

Gadahi, JA, Arshed, A, Javaid, SB, Shah, SI, 2009: Prevalence of Gastrointestinal Parasites of Sheep and Goat in and around Rawalpindi and Islamabad, Pakistan. Vet. World 2, 2:51-3.

Islam, MS, Hossain, M, Dey, A, Abdul Alim, M, Akter, S, et al, 2017: Epidemiology of gastro-intestinal parasites of small ruminants in Mymensingh, Bangladesh. J. Adv. Vet. Anim. Res. 4, 4: 356-62.

Johnson, DA, Behnke, JM, Coles, GC, 2004: Copro-antigen capture ELISA for the detection of Teladorsagia (Ostertagia) circumcincta in sheep: Improvement of specificity by heat treatment. Parasitology 129:115-26.

Khabisi, SA, Sarkari, B Moshfe, A, Jalali, S, 2017: Production of monoclonal antibody against excretory-secretory antigen of Fasciola hepatica and evaluation of its efficacy in the diagnosis of fascioliasis. Monocl. Antibody Immunodiag. Immunother. 36, 1:1-7.

Little, SE, Barrett, AW, Bowman, DD, Dangoudoubiyam, S, Elsemore, DA, et al, 2019: Copro-antigen detection augments diagnosis of common nematode infections in dogs. Top. Compan. Anim. Med. 35:42-6.

Liu, LN, Jing, FJ, Cui, J, Fu, GY, Wang, ZQ, 2013: Detection of circulating antigen in serum of mice infected with Trichinella spiralis by an IgY-IgMmAb sandwich ELISA. Exp. Parasitol. 133, 2: 150-5
Lowry, OH, Rosenbrough, NJ, Farr, AL Randall, RJ, 1951: Protein measurement with folinphenol reagent. J. Biol. Chem. 193:265-75. Mancera, AV, Mendoza, PM, Guzman, KH, Perez, JO, Perez, JS, et al, 2016: Comparativediagnosis of serum IgG1 and coproantigen ELIZA for fascioliasis detection of goats in Mexico. SA Bio. Med. Res. Int. 6:1-7.

McHardy, IH, Wu, M, Shimizu-Cohen, R, Couturier, MR, Humphries, RM, 2014: Detection of intestinal protozoa in the clinical laboratory. J. Clin. Microbiol. 52, 3:712-20.

Meradi, S, Cabaret, J, Bentounsi, B, 2016: Arrested development of abomasal trichostrongylid nematodes in lambs in a steppe environment (North-Eastern Algeria). Parasite 23:23-39. Mezo, M, Warleta, MG, Carro, C, Ubeira, F M, 2004: An ultrasensitive capture ELISA for detection of Fasciola hepatica coproantigens in sheep and cattle using a monoclonal antibody (MM3). J. Parasitol. 90, 4:845-52.

Roeber, F, Jex, AR, Gasser, RB, 2013: Impact of gastrointestinal parasitic nematodes of sheep and the role of advanced molecular tools for exploring epidemiology and drug resistance: An Australian perspective. Parasit. Vector. 6:153-9.

Rojas, CA, Jex, A, Gasser, R, Scheerlinck, P, 2014: Diagnosis of Fasciola infections in animal: Room for improvement. Adv. Parasitol. 85: 65-107.

Shalaby, SI, El-Bahy, M, Shalaby, SIA, Shalaby, H, Gupta, N, et al, 2014: Detection of copro-antigens by sandwich ELISA in rabbits experimentally infected with Fasciola gigantica. Iran. J. Parasitol. 9, 3:374-81.

Soulsby, EJ, 1986: Helminths, Arthropods, and Protozoa of Domesticated Animals (textbook). Williams and Wilkins Company, Baltimore. $\left(7^{\text {th }}\right.$ Ed.), Tindall and Cassel LTD

Sun, GG, Wang, ZQ, Liu, CY, 2015: Early serodiagnosis of trichinellosis by ELISA using excretory-secretory antigens of Trichinella spiralis adult worms. Parasit. Vector. 8:484-8.

Wyk, VJ, Mayhew, E, 2013: Morphological identification of parasitic nematode infective larvae of small ruminants and cattle: A practical lab guide. Onderstepoort. J. Vet. Res. 80, 1:1-14. Zimmerman, GL, Jen, LW, Cerro, JE, Farnsworth, LL, Wescott, RB, 1982: Diagnosis of Fasciola hepatica infections in sheep by an enzyme-linked immunosorbent assay. Am. J. Vet. Res. 43:2097-100. 